\title{
Efficiency Optimization of Induction Motor Drive using Soft Computing Techniques
}

\author{
K.Ranjith Kumar \\ Senior Lecturer \\ Dept. of Electrical Engineering \\ Govt College of Technology, \\ Coimbatore, Tamil Nadu, India.
}

\author{
D.Sakthibala, \\ PG Scholar \\ Power Systems Engineering \\ Govt College of Technology, \\ Coimbatore, Tamil Nadu, India.
}

\author{
Dr.S.Palaniswami \\ Professor \\ Dept. of Electrical Engg., \\ Govt College of Technology \\ Coimbatore, Tamil Nadu, India.
}

\begin{abstract}
This paper presents a new approach that minimizes copper \& iron losses and optimizes the efficiency of a variable speed Induction motor drive. This method is based on a simple induction motor field oriented control model includes iron losses uses only conventional IM parameters. In literature, Fuzzy logic and Genetic Algorithms have been used for efficiency optimization of induction motor drives. This paper proposes integration of Fuzzy model identification and PSO algorithm for loss minimization. An improvement of efficiency is obtained by adjusting the magnetizing current component with respect to the torque current component to give the minimum total copper and iron losses. The whole circuit is simulated using MATLAB 7.6. The proposed method is compared with other soft computing techniques. The results obtained by Fuzzy PSO shows better results compared with other approaches.
\end{abstract}

\section{General Terms}

Algorithms, Performance, Verification

\section{Keywords:}

Efficiency, Optimization, Field-Oriented Control (FOC), Induction Motor (IM), Fuzzy Controller Design, Genetic Algorithm (GA), Particle Swarm Optimization(PSO).

\section{INTRODUCTION}

The utility of induction motors are more than $50 \%$ of the total electric energy generated worldwide. A small improvement in efficiency would significantly save the total electric energy. Hence, it is important to optimize the efficiency of motor drive systems if significant energy savings are to be obtained. The induction motor(IM), especially the squirrel-cage type, is widely used in electrical drives and is responsible for most of the energy consumed by electric motors [5].

The IM losses can be classified as stator copper losses, rotor copper losses, iron losses, stray losses and mechanical (friction + windage) losses. The main losses, about $80 \%$ of the total losses, are copper (stator + rotor) and iron losses. The focus of this paper is on the minimization of these losses which will be referred to collectively as electromagnetic losses. However, there are many applications which require adjustable torque and /or speed. If these parameters vary far from the rated operating point causes a notorious IM efficiency drop.

This is due to the imbalance between iron and copper losses. Under these circumstances, it is not possible to increase the efficiency by the improvement of the machine design. Although different variables have been controlled, in all these methods the efficiency improvement is always achieved by indirectly controlling the balance between copper and iron losses.
The mechanism that permits the electromagnetic loss minimization acts as follows:

Electromagnetic torque is proportional to the vector product of the rotor magnetic flux and rotor current. It is thus possible to obtain the same torque with different combinations of flux and current values. For a given torque, the iron loss can be minimized by using the minimum possible flux. This also minimizes the stator copper loss component due to the magnetizing current.

On the other hand, to create the required torque with less magnetizing flux, the rotor current must be increased by increasing the stator current and, consequently, the total copper losses.

By a proper adjustment of the magnetic flux, an appropriate balance between copper and iron losses can be achieved to minimize the electromagnetic losses. Almost all the methods reported for minimizing the IM losses have been developed for steady-state operation or very slowly changing conditions. This excludes their use when the dynamic response is also important [5].

In many applications efficiency optimization of induction motor (IM) which is the most used electrical motor presents an important factor of control especially for autonomous electrical traction. The very extensive use of induction motor implies that if losses in IM drives can be reduced by just a few percent, it will have a major impact on the total electrical energy consumption [5] - [6].

In high dynamic performances control schemes used in industrial applications like vector control and direct torque control, the flux is usually maintained constant equal to its nominal value; in this situation the induction motor run efficiently around the nominal point [6]. When the load is reduced considerably, the efficiency is also greatly reduced and the electrical energy consumption is then highly affected

To solve this problem, many approaches have been developed in order to obtain a highly efficient IM drives as discussed above. In this work, the approach used is based on genetic algorithm (GA) developed by J.Holland during the 1960's. The GA is basically a stochastic searching algorithm inspired by principle of the natural evolution of species. It is capable to solving non smooth, non continuous and non- differentiable problems for parallel computation to find global or near global optimal solutions [7] comparison between conventional optimization techniques and GA is presented in Table 1.

In this paper, Fuzzy model identification through PSO is employed to minimize the IM losses in order to evaluate the optimal magnetizing current, thus maximizing efficiency. In this study, the motor model includes iron losses. Simulation results are compared with those obtained with the conventional method and the proposed method. 


\section{METHODS OF LOSS REDUCTION AND CONTROL TECHNIQUES}

Losses in an IM constitute copper loss and core loss in stator and rotor, mechanical loss, and stray load loss. Core loss and copper loss depend on the magnetic and electric loading of the machine and, therefore, are controllable. The stray load loss depends mainly on the construction of the motor (type of stator and rotor slots, length of overhang, etc.) and also on the harmonics in the supply voltage. Usually, for a given motor and specified load, the sum of stray load loss and the mechanical loss do not exceed $30 \%$ of the total losses and may be assumed to remain constant. Thus, the motivation of loss minimization is to look for an optimum balance of the variable losses to make the total loss minimum. So far, efforts on loss minimization are put into three major directions: 1) through improved design of the motor and converter; 2) by better management to operate a group of motors in a more efficient way; and 3) by introducing better control techniques. Therefore, investigation is focused on better control techniques to yield loss minimization [8].

\subsection{Loss Model Control (LMC)}

Based on the IM loss model the optimum flux is computed analytically. Without extra hardware, LMC can be conveniently realized. However, it must need an accurate knowledge of motor parameters, which change considerably with temperature, saturation, skin effect, etc [9].

\subsection{On-Line Power Measure Search Control}

Based on minimum input power control, SC use particular search algorithms to find the optimum flux [10]-[11]. This approach does not require the knowledge of motor parameters. But the optimum flux search time is longer than that of LMC. In these search methods, the fuzzy logic based search method is the more successful one. But the need of simulation calculation to get the coefficients of the FL scaling factors, no doubt, will limit the application of this method. Unlike such simulation method, the new gain derivative method presented by this paper, which makes full use of the results of LMC, is simple and effective. Moreover, new fuzzy sets are designed to get over the oscillations around the optimum flux. The simulation of IM verifies that this strategy is very fast and highly precise, and can be applied for any steady state of IM.

\section{PROBLEM FORMULATION-MOTOR LOSS MODEL}

\subsection{Losses of Induction Motor}

The d-q model for a three phase IM in the synchronous frame can be written, when selecting the stator currents (isd, isq) and the rotor fluxes ( $\Phi$ rd, $\Phi$ rq) as state variables as, [13]. The total loss equation is arrived from [3] \& [13].

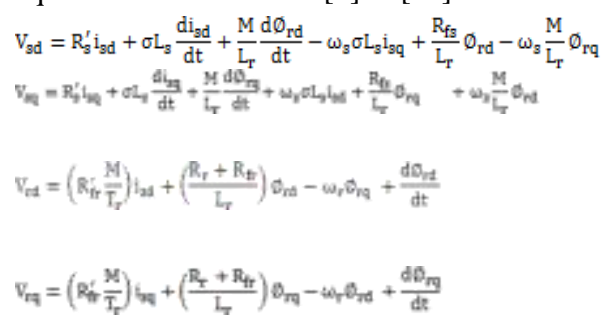

Where

\begin{tabular}{|c|c|c|c|}
\hline \multirow[b]{2}{*}{$\Delta \mathrm{I}_{\mathrm{sq}}$} & $\mathrm{I}_{\mathrm{sq}}$ & \multirow[t]{2}{*}{$\mathrm{Z}$} & \multirow[t]{2}{*}{$\mathrm{P}$} \\
\hline & $\mathrm{I}_{\mathrm{sd}}$ & & \\
\hline \multicolumn{2}{|l|}{$\mathrm{Z}$} & Z & $\mathrm{P}$ \\
\hline \multicolumn{2}{|l|}{$\mathrm{P}$} & $\mathrm{P}$ & $\mathrm{P}$ \\
\hline
\end{tabular}

The total losses of an IM consist of stator and rotor copper losses, core losses $\mathrm{P}_{\mathrm{fe}}$ and mechanical losses $\mathrm{P}_{\mathrm{m}}$. In the steady state the stator and rotor copper losses are defined as follows:

$P_{j g}=R_{g} \mid i_{g}^{2}\left\|^{2}=R_{g}\left(i_{\sigma d}^{2}+i_{g q}^{2}\right)\right\|$

$P_{j y}=R_{y}\left|i_{g}^{2} \|^{2}=\frac{R_{Y}}{\left(1+\sigma_{Y}\right)^{2}}\left[\left(i_{\mu Y}-i_{g d}\right)^{2}+i_{g q}^{2}\right]\right|$

The core losses including the eddy current and hysteresis losses are given by:

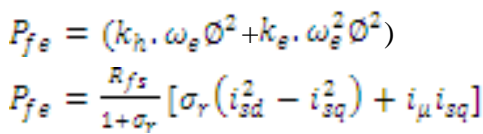

The coefficients of hysteresis and eddy current losses may be expressed as $\mathrm{k}_{\mathrm{h}}$ and $\mathrm{k}_{\mathrm{e}}$ respectively which can be determined from standard no-load test data, [13].As a reasonable approximation, the mechanical losses are dependent on the rotor speed, [10]. They can be expressed by:

$\mathrm{P}_{\mathrm{m}}=\mathrm{k}_{\mathrm{m}} \omega_{\mathrm{r}}^{2}$

Where $\mathrm{k}_{\mathrm{m}}$ is the mechanical loss coefficient.

As the stator currents isd and isq are regulated and the motor is controlled to be field oriented to the rotor flux, according to the following relation:

$$
\mathrm{i}_{\mathrm{dr}}=0 \text { andi } \mathrm{iqr}_{\mathrm{r}}=\frac{-\mathrm{MI}_{\mathrm{g}}}{\mathbb{L}_{\mathrm{R}}}
$$

Insteady,the operating losses of the machine can be expressed as follows:

$\mathrm{R}_{\text {loss }}=\mathrm{P}_{1 \mathrm{~s}}+\mathrm{P}_{\mathrm{I}}+\mathrm{P}_{\mathrm{fe}}+\mathrm{P}_{\mathrm{m}}$

The motor torque can be expressed as

$\mathrm{T}_{\mathrm{e}}=\frac{\mathbb{a}}{2} \mathrm{p} \frac{\mathrm{MI}}{\mathrm{L}_{\mathrm{r}}} \mathrm{Q}_{\mathrm{r}} \mathrm{1}_{3 \mathrm{~g}}$

$P_{\text {Loss }}=\left(R_{S}+R_{F s}\right) I_{N}^{2}+\left(R_{S}+\frac{R_{R}}{\left(1+\Sigma_{R}\right)^{2}}\right)\left(\frac{T_{E}}{P(1-\Sigma) L_{S} I_{N}}\right)^{2}+K_{N S} n_{R}^{2}$

\section{LOSS MINIMIZING STRATEGY}

\subsection{Control Block Diagram}


A simplified block diagram of the optimization procedure is depicted in Figure.1; it is implemented in classical rotor flux oriented control (FOC). In this scheme fuzzy PSO optimization algorithm is proposed, where two phase currents and the rotor speed are measured in order to calculate

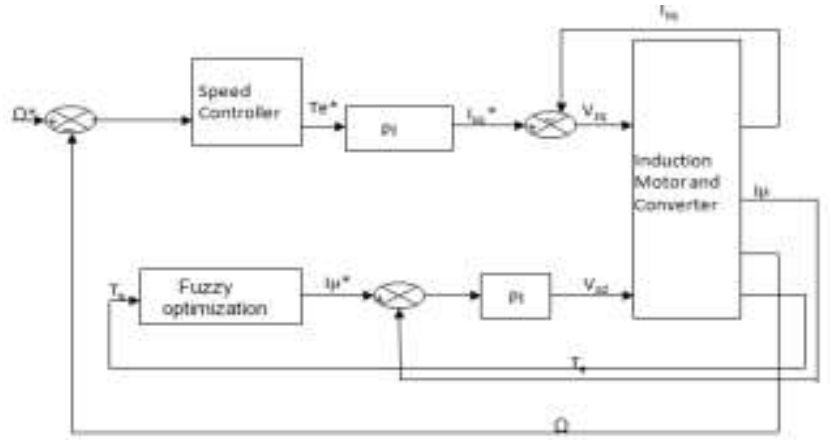

Figure 1. Block diagram of the optimization control system

the electromagnetic torque and the magnetizing current $\left(i_{\mu}\right)$ which enables us to express the total motor losses.

\section{FUZZY LOGIC APPROACH}

The fuzzy logic is an aggregation of rules, based on the input state variables condition with a corresponding desired output. A mechanism must exist to decide on which output, or combination of different outputs, will be used since each rule could conceivably result in a different output action. Fuzzy logic provides machinery for carrying out approximate reasoning processes when the available information is uncertain, incomplete or vague. The success of this methodology has been demonstrated in a variety of fields. Several fuzzy logic based efficiency controllers have been reported in literature, [9]-[10]. A fuzzy logic controller essentially embeds the experience and intuition of a human plant operator, and sometimes those of the designer of the plant, [13].

\subsection{Fuzzy Controller Design}

According to the optimization principle based on Figure.2, two input variables are considered, the torque current component $I_{s q}$ and its variation $\Delta \mathrm{I}_{\mathrm{sq}}$. The output of the fuzzy controller is the stator current component Isdn, which is calculated to minimize both copper and iron losses. The above inputs and output variation domains are limited and normalized as follows, [13]-[14]: Control rules are extracted and summarized in Table 1

$$
\begin{gathered}
I_{\text {sqn }}=\left|\frac{I_{\text {sq }}}{I_{\text {sqmax }}}\right| \\
\Delta I_{\text {sqn }}=\left|\frac{\Delta I_{\text {sq }}}{\Delta I_{\text {sqmax }}}\right| \\
I_{\text {sdn }}=\left|\frac{I_{\text {sd }}}{I_{\text {sdmax }}}\right|
\end{gathered}
$$

Table 1.Fuzzy Rules (Z: Zero, P:Positive)
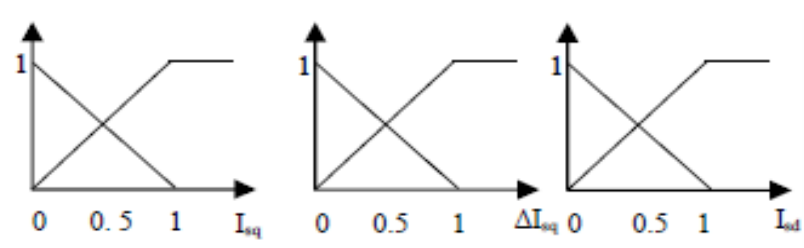

Membership Functions

Figure 2. Membership Functions for proposed scheme

\section{GA OPTIMIZATION PROCEDURE}

The GA was introduced by J. Holland during the 1960's. It is known as a stochastic searching algorithm inspired by principle of the natural evolution of species. This tool is defined as stochastic optimization technique based on the genetic natural evolution mechanism of creative beings. Such algorithm is found to be a powerful computational tool in seeking optimums and is considered as the most up-to-date product of artificial intelligence techniques that emulate the mechanics of natural selection and genetics. It explores, with coding parameter set, the workspace by means of mechanism of reproduction, with the target of optimizing the process selection. This mechanism comprises selection, crossover and mutation operations. In this case, this optimization procedure consists of searching the optimum magnetizing current (flux) value for a given load torque by relying on GA. The loss equation [3] can be expressed as

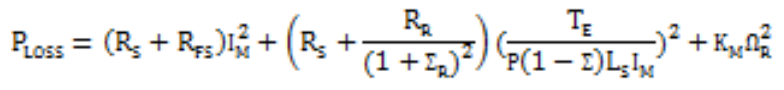

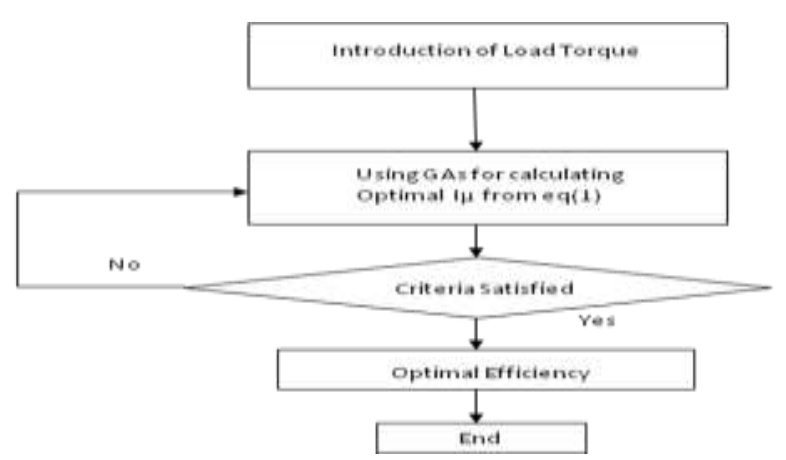

Figure 3. Flowchart for Efficiency Optimization by Gas

This approach requires the introduction of an objective function (17) which evaluates how much good the fitted values of the magnetizing current are. From this function, a fitness that controls the reproduction process is derived. The individuals of the initial GA population are encoded in binary strings where each individual representing a parameter takes 10 bits. The input (load torque) and optimized output (I $\mu)$ are shown in the Figure 3. The criterion to select the best individuals for reproduction is the objective (fitness) function. By proceeding in this way, the objective function adopted for this problem is the IM total losses given by equation (17). Each generation is subjected to the crossover and mutation mechanisms. The crossover consists in 
randomly selecting a position along parents string a swapping all binary digits following that position. The mutation follows crossover and works by randomly selecting one sting and one bit location, changing that strings bit from 1 to 0 or vice versa. The probabilities of the crossover and mutation are set to 0.8 and 0.01 respectively. The optimized $(\mathrm{I} \mu)$ is used in the induction motor stator controller for improving the performance of the induction motor.

\section{FUZZY MODEL IDENTIFICATION THROUGH PSO}

The origin of PSO is best described as sociologically inspired, since it was initially developed as a tool by Reynolds for simulating the flight patterns of birds, which was mainly governed by three major concerns: collision avoidance, velocity matching and flock centering [17]. Like evolutionary computation techniques, it uses a population of potential solutions called particles that are flown through the hyperspace/search-space. In $\mathrm{PSO}$, the particles have an adaptable velocity that determines their movement in the search-space. Each particle also has a memory and hence it is capable of remembering the best position in the search-space ever visited by it. The position corresponding to the best fitness is known as pbest and the overall best out of all the particles in the population is called gbest. Consider that the search-space is d-dimensional and i-th particle in the swarm can be represented by $\mathrm{Xi}=(\mathrm{xi} 1, \mathrm{xi} 2, \ldots, \mathrm{xid})$ and its velocity can be represented by another d-dimensional vector $\mathrm{Vi}=(\mathrm{vi} 1, \mathrm{vi} 2, \ldots$, vid). Let the best previously visited position of this particle be denoted by $\mathrm{Pi}=$ (pi1, pi2, ...,pid).If $\mathrm{g}$-th particle is the best particle and the iteration number is denoted by the superscript, then the swarm is modified according to the Eqs. (18) and (19).

$$
\begin{aligned}
& w_{i d^{n+1}}^{n+1}=w w_{i d}^{n}+c_{1} x_{1}^{n}\left(p_{i d}^{n}-x_{i d}^{n n}\right)+c_{2} x_{2}^{n}\left(p_{g} d^{n}-\right. \\
& \left.x_{i d}^{n}\right) \\
& x_{i d^{n+1}}=x_{i d^{n}}+w_{i d^{n+1}}^{n}
\end{aligned}
$$

where,

$\mathrm{w}$ - inertia weight

$\mathrm{c} 1$ - cognitive acceleration

c2 - social acceleration

$\mathrm{r} 1, \mathrm{r} 2$ - random numbers uniformly distributed in the range $(0,1)$. The parameter $\mathrm{V}_{\max }$ is the maximum velocity along any dimension, which implies that, if the velocity along any dimension exceeds $V_{\max }$, it shall be clamped to this value. The inertia weight governs how much of the velocity should be retained from the previous time step. Generally the inertia weight is not kept fixed and is varied as the algorithm progresses so as to improve performance.

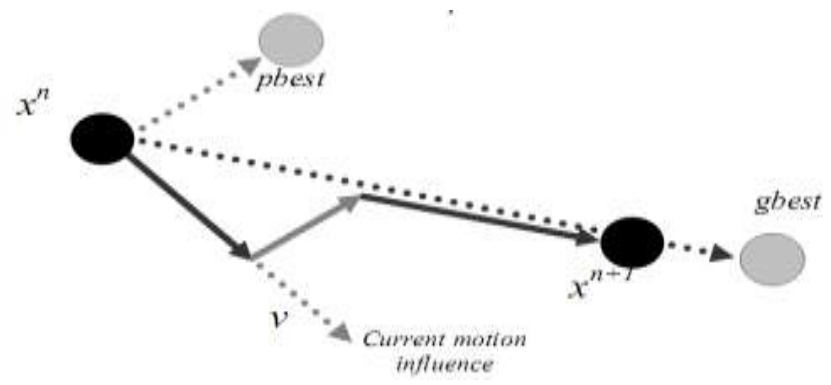

Figure 4. Depiction of position updates in particle swarm optimization for 2-D parameter space

\subsection{Fuzzy Model Identification Problem}

The problem of fuzzy model identification includes the following issues:

- $\quad$ Selecting the type of fuzzy model

- Selecting the input and output variables for the model

- Identifying the structure of the fuzzy model, which includes determination of the number and types of membership functions for the input and output variables and the number of fuzzy rules

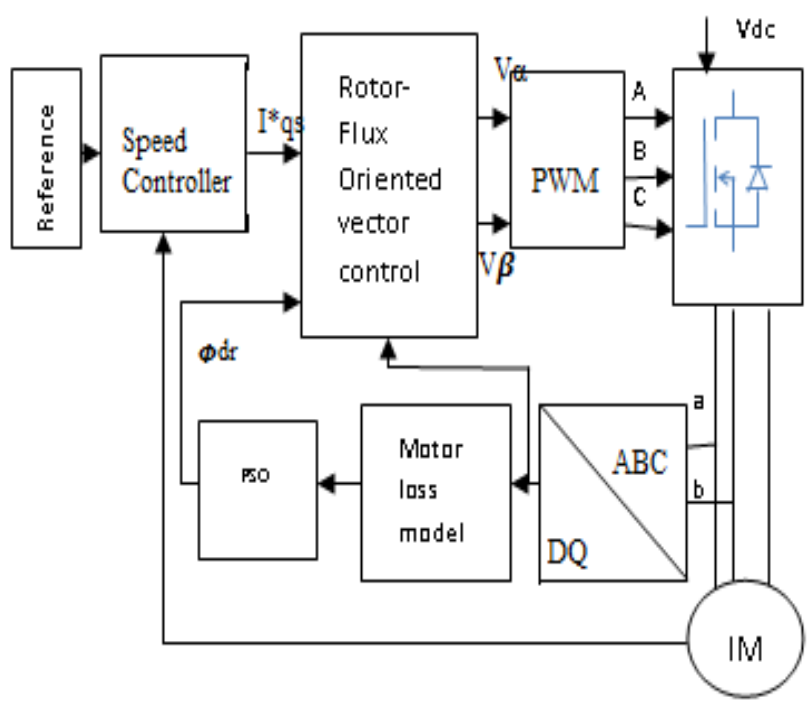

Figure 5. Proposed Loss minimization algorithm

- Identifying the parameters of antecedent and consequent membership functions

- Identifying the consequent parameters of the fuzzy rule base.

The objective of optimization problem is to look for the values of the variables being optimized, which satisfy the defined constraints, which maximizes or minimizes the fitness function. In this paper Mean Square Error (MSE) defined in Eq. (20) is used as fitness/objective function for rating the fuzzy model.

MSE $=\frac{1}{z} \sum_{k=1}^{z}[y(k)-\tilde{y}(k)]^{2}$

where,

$\mathrm{y}(\mathrm{k})$ - desired output

$\hat{y}(\mathrm{k})$ - actual output of the model

$\mathrm{Z}$ - number of data points taken for model validation

A very important consideration is to completely represent a fuzzy system by a particle, and for this, all the needed information about the rule-base and membership functions is required to be specified through some encoding mechanism. It is also suggested to modify the membership functions and rule-base simultaneously, since they are codependent in a fuzzy system. 


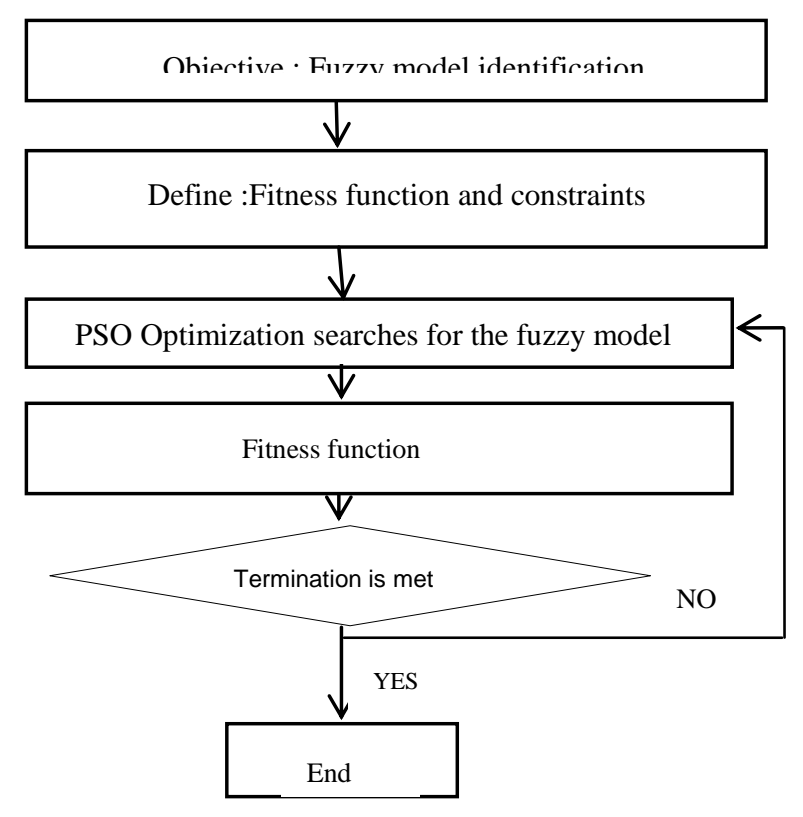

Figure 6. Flowchart for the PSO algorithm

\subsection{Algorithm of PSO}

Step 1 -Define fitness function

Step 2 -Initialize the particles of the population according to the limits. Initialize parameters $\mathrm{W}_{\max }, \mathrm{Wmin}, \mathrm{C}_{1}, \mathrm{C}_{2}$ and iter ${ }_{\max }$

Step 3 -Generate initial population of $\mathrm{N}$ particle with random position and velocities

Step 4 - calculate fitness: Evaluate the fitness values of current particle using the objective function Eq.(20)

$$
M S E=\frac{1}{z} \sum_{k=1}^{z}[\mathcal{F}(k)-\mathscr{y}(k)]^{2}
$$

Step 5 - Update Pbest: Compare the fitness value of each particle with its pbests. If the current value is better than pbest, then set pbest value to the current value.

Step 6 - Update gbest: Compare the fitness value of each particle with its gbests. If the current value is better than pbest, then set pbest value to the current value.

Step 7 -If the number of iterations reaches the maximum, then go to Step 8.Otherwise, go to Step 4.

Step 8 -The particle that generates the latest gbest is the solution of the problem.

Step 9 - Stop

\subsection{Encoding Mechanism}

The following constraints are followed by every membership function of input and output variables.

$$
x_{k}{ }^{l}<x_{k}{ }^{c}<x_{k}{ }^{r}
$$

Particle Size $=2 \mathrm{~m}_{\mathrm{i}}-2$

Thus the particle size for representing the membership functions of input and output variables for a Mamdani model is given by Eq. (21).
Particle Size (for membership functions)=

$$
\sum_{i=1}^{n+1}\left(2 m_{i}-2\right)
$$

Particle Size(for rule base) $=\prod_{i=1}^{n} m_{i}$

Particle Size(for membership

functions $)=\sum_{i=1}^{n+1}\left(2 m_{i}-2\right)+\prod_{i=1}^{n} m_{i}$

\subsection{Fuzzy Model Identification through PSO: A Matlab Implementation}

Table 2. List of Matlab functions

\begin{tabular}{|c|l|}
\hline i) & Random Particle \\
\hline ii) & Limit swarm \\
\hline iii) & Limit Particle \\
\hline iv) & Limit Membership Functions \\
\hline v) & Limit rules \\
\hline vi) & Get FIS \\
\hline vii) & Calculate MSE \\
\hline
\end{tabular}

Table 3. Strategy parameters for Identification of fuzzy model

\begin{tabular}{|l|c|}
\hline Swarm Size & 30 \\
\hline Iterations & 2500 \\
\hline $\mathrm{C}_{1}$ & 2 \\
\hline $\mathrm{C}_{1}$ & 2 \\
\hline $\begin{array}{l}\mathrm{W}_{\text {start }} \text { (Inertia weight at } \\
\text { the start of PSO run) }\end{array}$ & 0.9 \\
\hline $\begin{array}{l}\mathrm{W}_{\text {end }} \text { (Inertia weight at the } \\
\text { end of PSO run) }\end{array}$ & 0.3 \\
\hline $\mathrm{V}_{\text {max }}$ & 75 \\
\hline
\end{tabular}

\section{RESULTS AND DISCUSSION}

In order to fulfill the IM energy saving task by the proposed approaches, a numerical simulation has been carried out using Matlab/Simulink software. The nameplate-rated characteristics of the induction machine with its model parameters used in the simulation are shown in Table 5. The Proposed fuzzy PSO optimization procedure has led to an optimal vector of magnetizing current (i $\mu$ ) values for several loads. These obtained results are then introduced in a lookup table and finally inserted in the control block. As it is apparent the efficiency is greatly improved over a wide range when using those methods compared with the conventional method. The fuzzy PSO results are greatly improved particularly over the light load region through which habitually the efficiency values are relatively low. 


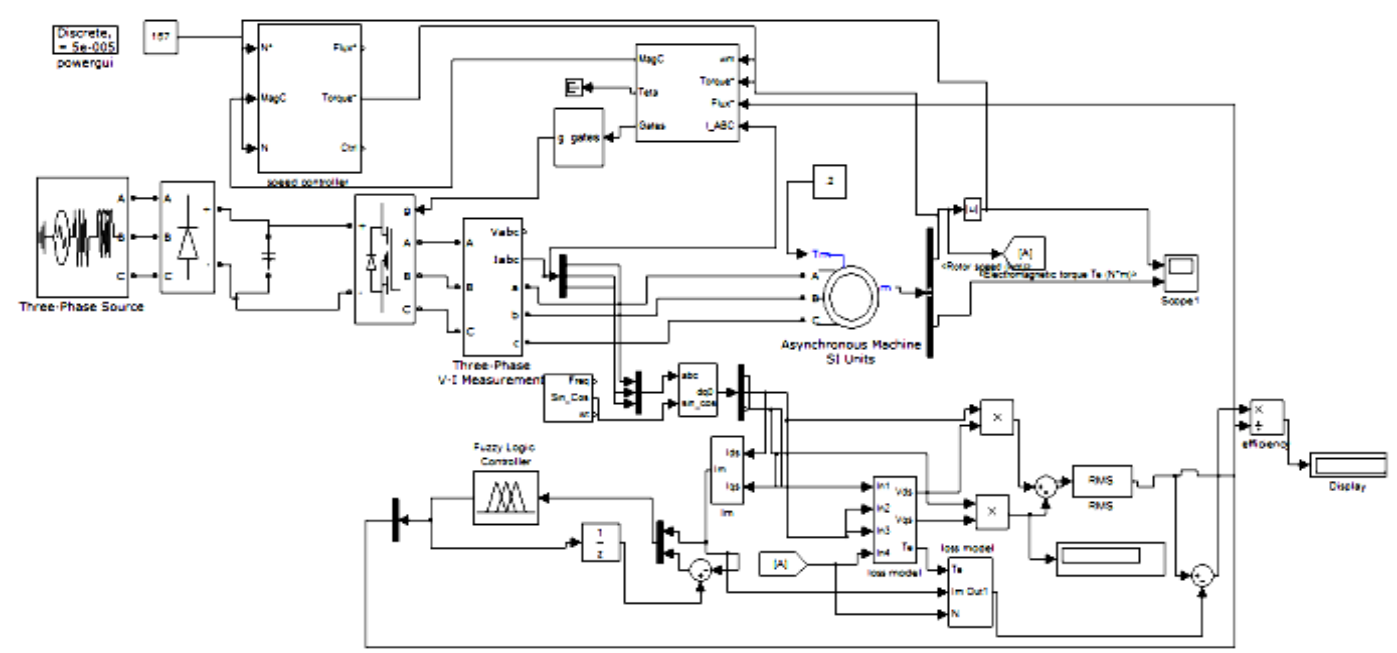

Figure 7. Matlab Simulation model of fuzzy controller based optimization of Induction motor

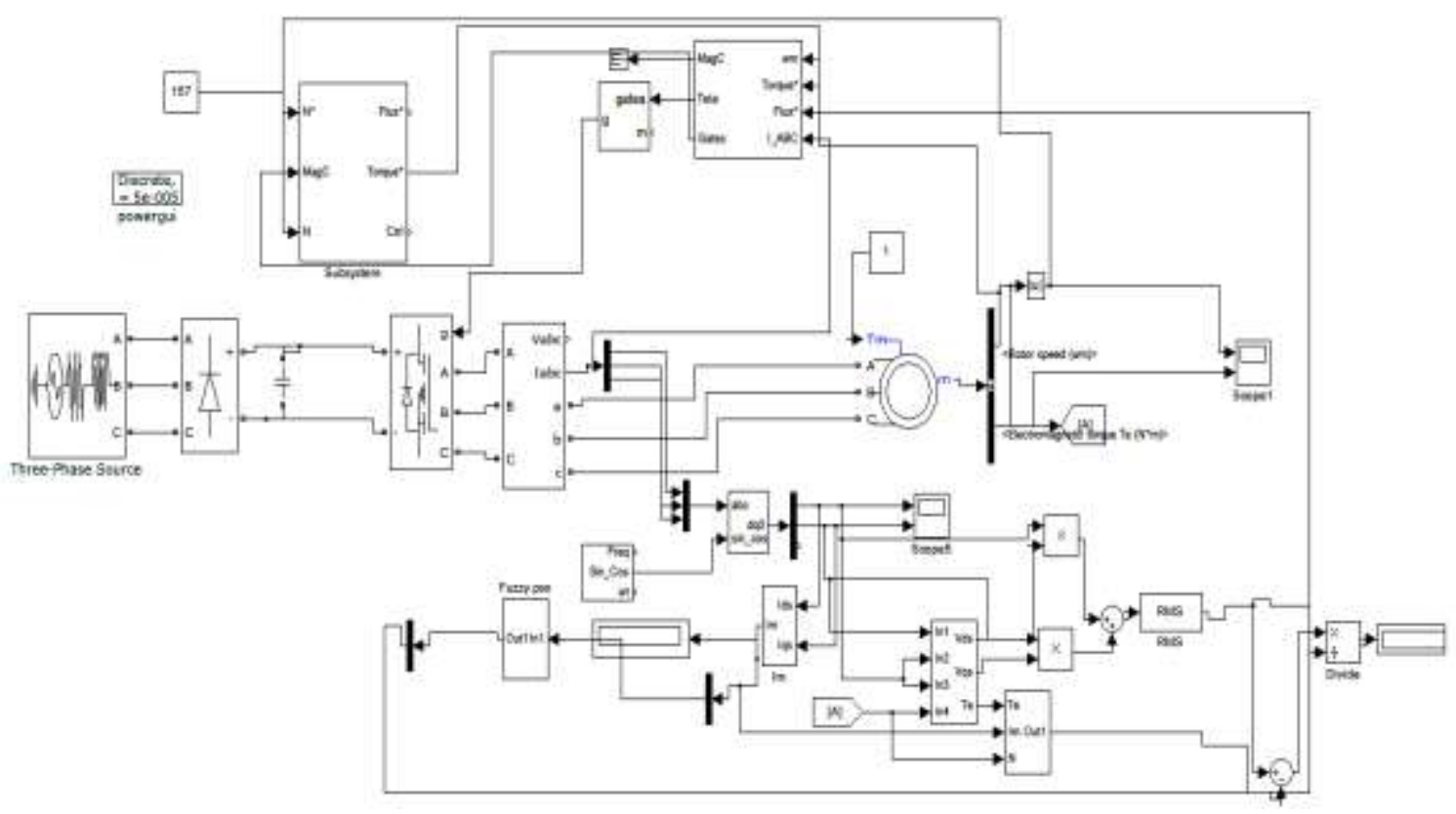

Figure 8. Matlab Simulation of Fuzzy PSO based optimization of Induction motor

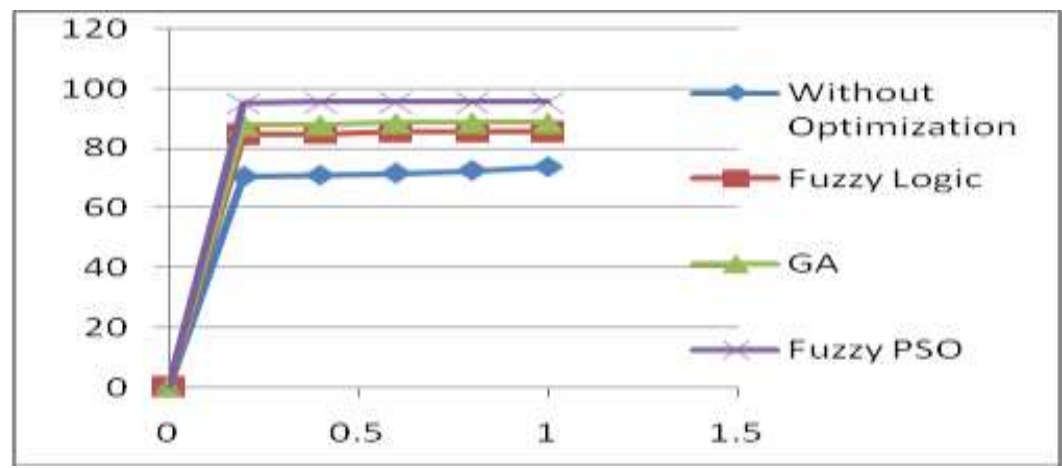

Figure 9. Efficiency Vs Load for different optimization techniques 
Table 4. Comparison of efficiency values of different optimization techniques

\begin{tabular}{|c|c|c|c|c|}
\hline Load & \multirow{2}{*}{$\begin{array}{c}\text { Without } \\
\text { Optimization }\end{array}$} & \multicolumn{3}{|c|}{ Proposed Approach } \\
\cline { 3 - 5 } & & Fuzzy logic & GA & Fuzzy PSO \\
\hline 0.2 & 70.78 & 84.41 & 87.81 & 95.21 \\
\hline 0.4 & 71.18 & 84.84 & 88.81 & 95.48 \\
\hline 0.6 & 71.88 & 85.35 & 88.5 & 95.46 \\
\hline 0.8 & 72.8 & 85.43 & 88.67 & 95.31 \\
\hline 1 & 73.97 & 85.53 & 88.63 & 95.33 \\
\hline
\end{tabular}

Table 5. Rating and Parameters of Induction Motor

\begin{tabular}{|l|c|}
\hline Power P & $4 \mathrm{~kW}$ \\
\hline Number of pairs of poles $\mathrm{np}$ & 2 \\
\hline Stator resistance Rs & $1.15 \Omega$, \\
\hline Rotor resistance Rr & $1.44 \Omega$ \\
\hline Total leakage factor $\sigma$ & 0.12, \\
\hline Mutual inductance M & $0.143 \mathrm{H}$ \\
\hline $\begin{array}{l}\text { Stator and rotor self- } \\
\text { inductance = Lr }\end{array}$ & $0.156 \mathrm{H}$ \\
\hline Inertia J & $0.0240 \mathrm{SI}$ \\
\hline Viscous friction coefficient $\mathrm{f}$ & $0.00 \mathrm{SI}$ \\
\hline \multicolumn{1}{|c|}{ Rated Load torque TL } & 7 N.m \\
\hline
\end{tabular}

The equivalent core losses resistance is given by,:

$$
R_{f}=A \cdot f+B \cdot f^{2}
$$

Where:

A, B: constants charactering the iron losses.
f: stator or rotor flux frequency

\section{CONCLUSION}

In this study, Soft computing approaches have been treated and applied to improve IM efficiency. The first approach is the application of fuzzy logic and the second one is the Fuzzy PSO. The adopted strategy consists of decreasing the rotor flux by adjusting the magnetizing current component with respect to the torque current one. The obtained optimized results of this investigation by these techniques in conjunction with those of conventional methods are illustrated graphically in Figures 9.

The use of PSO algorithm for identification of optimized fuzzy model from output data has been presented. They are of great interest since the IM efficiency is improved over a wide load operating range. Distinctively, those yielded from the fuzzy PSO technique are highly enhanced over the usually suffers of low efficiency values. From the presented study, one can conclude that this IM efficiency improvement strategy, implemented by fuzzy PSO, is very promising and leads to a significant energy saving under different load operating conditions.

\section{REFERENCES}

[1] B. K. Bose, 2002. Power Electronics and AC Drives, Prentice Hall, USA.
[2] D. E. Golberg, 1989. Genetic Algorithms in Search, Optimization and Machine Learning Reading, MA: AddisonWisley, USA.

[3] Z. Rouabah, F. Zidani, B. Abdelhadi, 2008. "Efficiency Optimization of Induction Motor Drive using Fuzzy Logic and Genetic Algorithms", Industrial Electronics, ISIE, pp 737-742.

[4] C. Thanga Raj, Member IACSIT, S. P. Srivastava, and Pramod Agarwal, April 2009. "Energy Efficient Control of Three-Phase Induction Motor - A Review", International Journal of Computer and Electrical Engineering, Vol. 1, No. 1, 1793-8198.

[5] D. S. Kirischen, D.W.Novoty and T. A. Lipo, March 1987. "Optimal Efficiency Control of an Induction Motor Drive”, IEEE Trans. On Energy Conversion, Vol. EC-2, No. 1, pp. 70-76.

[6] S. Ghozzi and all., Dec 2004. "Energy Optimization of Induction Motor Drives", IEEE International Conference on Industrial Technology (ICIT), 8-10, Vol. 2, pp. 602-610.

[7] G.B.Sheble and K.Briting, Feb 1995. "Refined Genetic Algorithm -Economic Dispatch Example", IEEETrans, On Power Systems, Vol.10N, pp.117-124.

[8] G. O. Garcia, J. C. Mendes Luis, R. M. Stephan, and E. H.Watanabe, October 1994. "An Efficient Controller for an Adjustable Speed Induction Motor Drive", IEEE Transactions on Industrial Electronics, Vol.41, No.5, pp 533 -539 .

[9] Zhang Liwei, Liujun, and Wen Xuhui, Member, 2005. "A few fuzzy logic based search control for efficiency optimization of induction motor drives" Power Engineering Conference, IPEC 2005. pp.1 - 526.

[10] Jie. Li and all., August 2005."Efficiency Optimization of Induction Machines Based on Fuzzy Search Controller", Proceeding of the Fourth International Conference on Machine Learning and Cybernetic, Guangzhou, 18-21, pp. 2518- 2522.

[11] Jinchuan. Li and all, May 2005. "A new Optimization Method on Vector Control of Induction Motors", Electric Machines and Drives, 2005 IEEE International Conference, 15-18, pp. 1995-2001.

[12] Chandan Chakraborty, Senior Member, and Yoichi Hori, Senior Member, IEEE, July/August 2003. "Fast Efficiency Optimization Techniques for the Indirect Vector-Controlled Induction Motor Drives", IEEE Transactions on Industry Applications, VOL. 39, NO. 4 pp 1070 - 1076.

[13] F. Zidani and all, October2000. "Fuzzy EfficientOptimization Controller for Induction Motor", IEEE Power Engineering Review, pp. 43-44.

[14] Z. Rouabah., Nov 2006. "Optimal Efficiency of a Fuzzy Controller in a Field Oriented Control Induction Motor Drive", 4th International Conference on Electrical Engineering CEE06, Batna, Algeria, 07 - 08, pp. 135-138.

[15] S. Lim and K. Nam, July 2004. "Loss-Minimizing Control Scheme for Induction Motors", IEE Proc. Electr. Power Appl., Vol. 151, N o. 4, pp. 385-397.

[16] J.M.D. Murphy and U.B.Honsinger, "Efficiency Optimization of Inverter-fed Induction Motor Drives", Conf. Rec.1982 IEEE Ind. Appl Soc., pp. 544-552.

[17] Arun Khosla , Shakti Kumar,, K.K. AGGARWAL, and Jagatpreet SINGH, 2006, “ Design of Fuzzy Models through Particle Swarm Optimization”, Integrated Intelligent Systems for Engineering Design, IOS Press, 